\title{
COMMUNICATIONS
}

\section{PITUITARY STALK SECTION FOR ADVANCING DIABETIC RETINOPATHY*}

\author{
BY \\ J. F. CULLEN, P. HARRIS, J. F. MUNRO, AND L. J. P. DUNCAN \\ From the Departments of Ophthalmology and Neurological Surgery, University of Edinburgh, \\ and the Diabetic Department, Royal Infirmary of Edinburgh
}

THE therapeutic possibilities of induced anterior pituitary insufficiency in diabetic patients were first raised by the studies of Luft, Olivecrona, and Sjögren (1952) and Luft, Olivecrona, Ikkos, Kornerup, and Ljunggren (1955), and by Poulsen's (1953) report of improvement of severe diabetic retinopathy in a patient who had developed post-partum hypopituitarism. Since then workers in several centres have attempted to treat severe and advancing retinopathy by pituitary ablation, and this has now become an established, though empirical, procedure. In 1962 Sprague summarized the results of pituitary surgery in 134 patients reported at a symposium of the American Diabetes Association, as follows:

"The procedures employed were hypophysectomy (103 patients), hypophyseal stalk section (twenty patients), and ${ }^{90}$ yttrium implantation (eleven patients).... Among the 119 patients who survived the various operative procedures there was, according to the authors' testimony, a favourable effect on the eyes in approximately seventy-five patients. In some of these there was measurable improvement in vision, while in others there was an arrest or apparent slowing of the progression of the retinopathy. However, the overall benefits of the procedure in the entire group of cases were lessened by the subsequent death of thirty-nine additional patients at intervals up to six years following the induction of pituitary insufficiency."

Of the twenty patients who underwent pituitary stalk section, three died within eight days of operation, one following operative cerebral haemorrhage and one as a result of an acute myocardial infarct. In the third there was an unexplained rise of blood pressure during the operation and post-mortem examination showed evidence of hypertensive encephalopathy. Two further patients died at intervals of two and eight months after operation and, in each case, death was attributed to irreversible hypoglycaemia.

In early 1962 we embarked on a trial of pituitary stalk section for advancing diabetic retinopathy. This procedure was preferred to formal hypophysectomy because it was thought to be easier, safer, and as effective in inducing the desired state of anterior pituitary insufficiency. 


\section{Selection of Patients}

(1) Ophthalmological Considerations

The retinopathy had to be of the haemorrhagic proliferative type which is most often seen in insulin-dependent diabetics of long standing, particularly if poorly controlled. The types of lesion most likely to respond favourably and regress are:

(a) Primary neovascularization or proliferations (formerly described as rete mirabile) (Fig. 1).

(b) Venous changes such as tortuosity, coiling, looping and "sausage string" formations.

Both of these give rise to superficial retinal, pre-retinal, and vitreous haemorrhages, the consequences of which are secondary neovascularization or proliferations (retinitis proliferans).

(c) Secondary neovascularization or proliferations (Fig. 2). Most of our patients showed this type of lesion where a vicious circle of bleeding and fibrosis had been established.
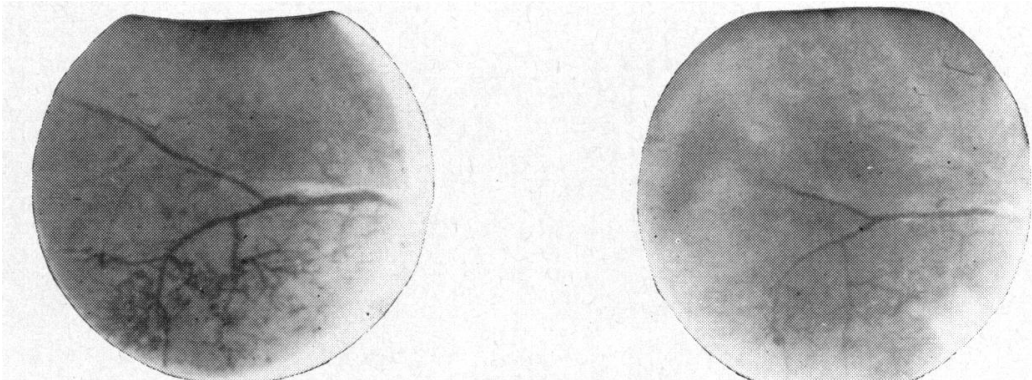

FIG. 1.-Case 1, right eye, localized area of primary neovascularization and venous changes before, and $2 \frac{1}{2}$ months after, pituitary stalk section.
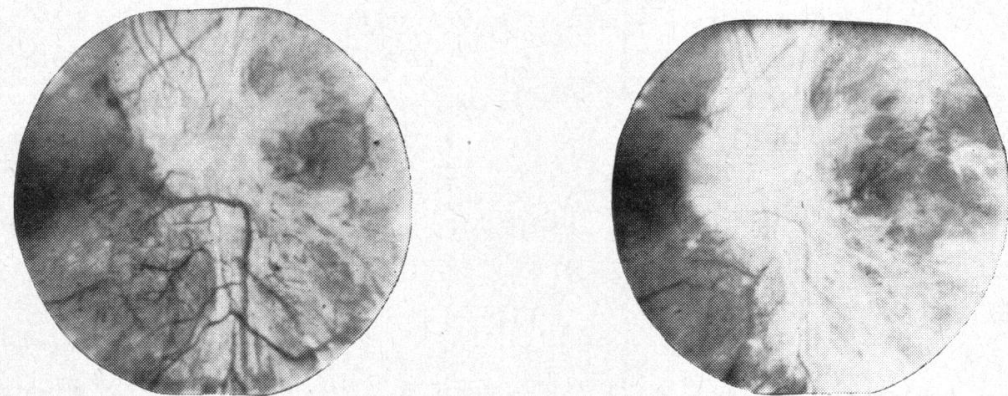

FIG. 2.-Case 1, right eye, secondary neovascularization before, and $2 \frac{1}{2}$ months after, pituitary stalk section.

Progression of retinopathy was confirmed by repeated examinations and photography of the fundi. Visual function was assessed by determination of corrected visual acuity for distance and near and by visual field examination. No patient whose corrected acuity was less than $\mathbf{N} 8$ in the better eye was considered, and only those who had experienced subjective symptoms, usually a vitreous haemorrhage, were operated upon. In those whose fundi were obscured by recent vitreous bleeding there had to be either documented evidence of the state of the retinae before the haemorrhage, or sufficient vitreous clearing to establish that the retinopathy was within the acceptable limits for selection. 


\section{(2) Medical Considerations}

A full general medical assessment was made in all patients and the presence of any disease likely to cause death within five years precluded surgery. Since severe retinopathy is always accompanied by diabetic nephropathy, renal status was determined by biochemical tests and histological examination of tissue obtained by renal biopsy (Table I).

To assess the effect of stalk section on pituitary function, base-line values for serum thyroid stimulating hormone and urinary gonadotrophins and ketosteroids were obtained when possible.

All patients were anxious to be operated upon, although they had been told that surgery might have no beneficial effect on vision, that it carried an immediate risk, and also had long-term effects with respect to child-bearing and hormone replacements.

\section{Surgery}

The diabetes was controlled pre-operatively in the manner described by Dunlop and Duncan (1957). Anaesthesia was induced by thiopentone and maintained by phenoperedine and a mixture of nitrous oxide and oxygen. Following induction of anaesthesia, the patient was maintained on the Barnet respirator and was given $500 \mathrm{ml}$. of 25 per cent. mannitol intravenously as a hypertonic agent. As a result the brain was slack and easy to retract. Hydrocortisone hemisuccinate $100 \mathrm{mg}$. was given intravenously. A coronal scalp flap was then turned forwards and a small right frontal bone-flap cut and turned laterally. The dura was opened along the lesser wing of sphenoid. After retracting the right frontal lobe upwards and backwards, the optic nerves and chiasma were revealed. The pituitary stalk was exposed and held forward with a blunt hook. It was then occluded with silver clips and sectioned with a knife, the site being carefully inspected to ensure that section was complete. A small piece of nylon film was placed across the site of section and anchored by a stitch to the dura of the floor of the anterior fossa. Haemostasis was secured and the wound closed in the usual manner.

\section{Post-operative Management}

The management of the immediate post-operative phase, which varied in duration from two to ten days, was directed towards maintaining the patient's general medical and metabolic state, in particular diabetic controler water and electrolyte balance. During this period regular observations, of pulse, blood pressure, level of consciousness, and neurological state were made. Blood was taken for electrolyte and blood-sugar estimations at frecfuent intervals and urine tested for glucose every three hours. Urine volumes were measured every six hours and urinary potassium and sodium estimated in the twenty-four-hour output. patients were given intravenous glucose, insulin, and appropriate quantities of sodium, potassium, chloride, and bicarbonate. During the first twenty-four hours $300 \mathrm{mg}$. of hydrocortisone hemisuccinate was given intravenously and thereafter reduced in dosage and finally replaced by a maintenance dose of oral cortisone acetate. 


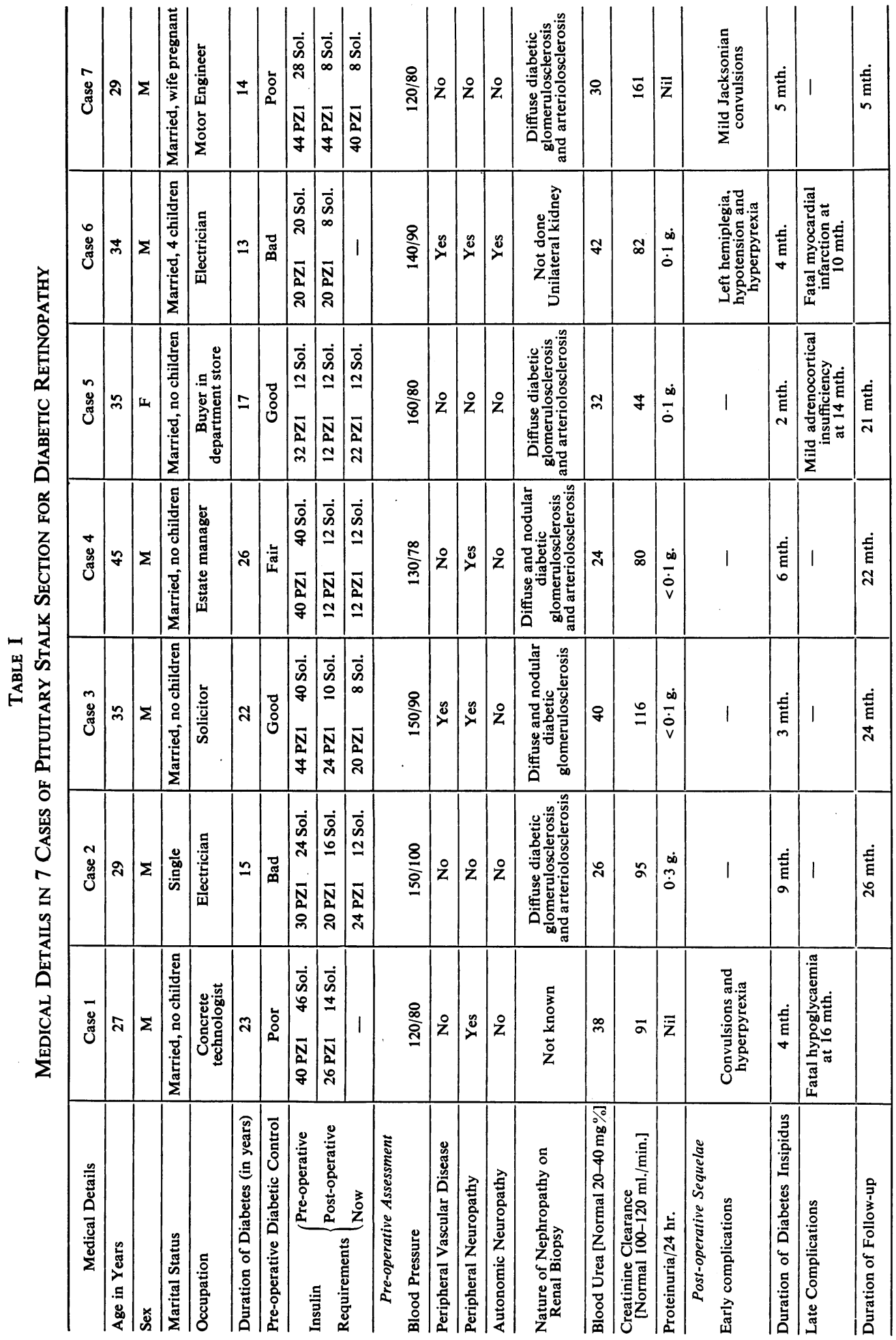


The problems anticipated or encountered were:

(1) Diabetic Control.-The increased insulin sensitivity induced by pituitary ablation was initially more than offset by the administration of large doses of corticosteroids, but became apparent as the dosage of the latter was reduced. Adjustments in daily insulin dosage thus had to be anticipated and the amounts of glucose and insulin given adjusted to maintain $\frac{1}{4}$ to $\frac{1}{2}$ per cent. glycosuria. Whenever a urine sample was glucose-free, 25 c.c. of 50 per cent. glucose was added to the intravenous infusion and, conversely, additional insulin was given whenever 2 per cent. glycosuria occurred. With this régime good diabetic control was maintained and hypoglycaemia was never a problem.

(2) Polyuria.-The occurrence of polyuria was due either to the mannitol diuresis, which wore off within eight hours of operation, to excessive glycosuria, which was corrected as mentioned above, or to diabetes insipidus, which developed in all patients within eighteen hours of operation. Whenever the urine volume markedly increased in the absence of 2 per cent. glycosuria, 10 units of pitressin tannate in oil were given intramuscularly. Thereafter patients required 5 to 10 units every twenty-four to forty-eight hours.

(3) Hyponatraemia.- Severe hyponatraemia was observed in the first patient treated and two others (Case 2 and Case 7) showed a considerable increase in urinary sodium loss (up to $600 \mathrm{mEq}$. per day). This developed in the second postoperative week and disappeared after three to six weeks. It occurred in the absence of 2 per cent. glycosuria or free diuresis, was not corrected by fludrocortisone, and was only corrected or prevented by appropriate replacement of urinary salt losses.

(4) Hyperpyrexia. - All patients showed a rise of temperature to at least $100^{\circ} \mathrm{F}$., but in only two did it exceed $101^{\circ} \mathrm{F}$. Marked elevations were considered to be cerebral in origin and responded to direct fan-cooling of the patient and small doses of chlorpromazine.

(5) Hypotension.-Severe post-operative hypotension occurred in one patient, together with hyperpyrexia and left hemiplegia (see Case 6).

(6) Convulsions.- Two patients had convulsions during the immediate postoperative phase, but these responded to phenobarbitone.

\section{Long-term Effects}

All patients needed permanent replacement therapy with cortisone acetate $(25 \mathrm{mg}$. to $37.5 \mathrm{mg}$. per day) and thyroxine $(0.2 \mathrm{mg}$. to $0.3 \mathrm{mg}$. per day). In addition, males were given subcutaneous testosterone implants as required $(400 \mathrm{mg}$. to $600 \mathrm{mg}$. every three to five months) and the female "Dianabol" (10 mg. per day) for its anabolic effect. All needed pitressin tannate to control the diabetes insipidus, which lasted for a variable length of time (see Table I).

The necessity for careful diabetic regulation was emphasized and patients were instructed to adjust the dosage of insulin to that which would keep the appropriate urine tests showing $\frac{1}{2}$ per cent. glycosuria on average, thereby reducing the danger of severe hypoglycaemia as a consequence of the increased insulin sensitivity. One patient (Case 1), however, died of hypoglycaemia. Two others (Cases 5 and 6) developed symptoms of adrenocortical insufficiency because the dose of cortisone was not increased sufficiently during intercurrent illness. 


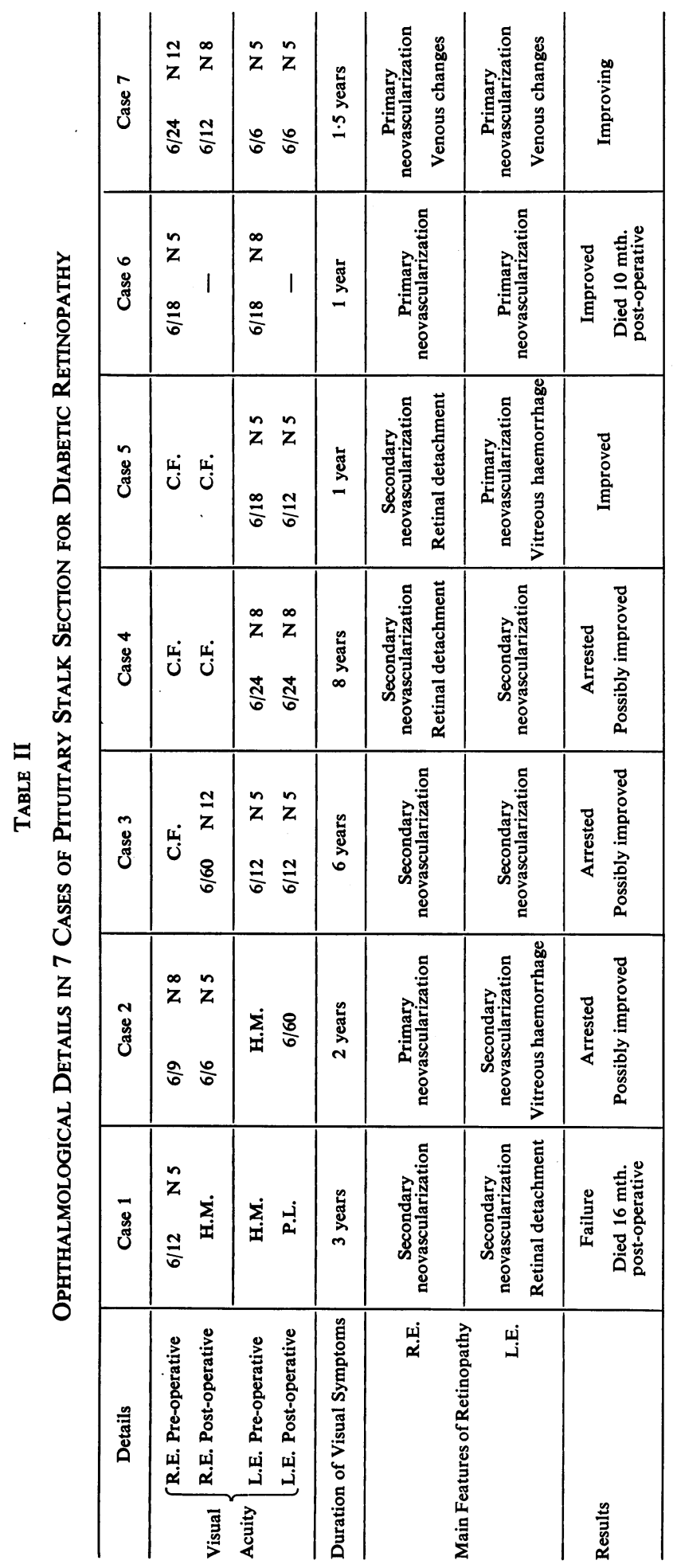




\section{Case Reports}

The relevant medical details are summarized in Table I. The ophthalmological histories are presented below and summarized in Table II.

Case 1.-This patient was referred in January, 1962. He had noticed fluctuating visual impairment in both eyes for three years; in March, 1961, he became blind in the left eye and in December of that year vision in the right eye suddenly deteriorated. Visual acuity in the left eye was reduced to perception of hand movements and in the right to 6/12 and N 5. Both fundi showed advanced venous changes and secondary neovascularization. Retinal detachment had occurred in the left eye and fresh haemorrhages were seen in the right, although the macular region remained relatively unaffected. While being assessed for surgery a further large vitreous haemorrhage in the right eye reduced its vision temporarily to $6 / 24$ and $N 24$, and pituitary stalk section was performed on February 2, in the hope that macular vision in this eye might be retained. After five weeks visual acuity in that eye had returned to $6 / 12$ and $\mathrm{N} 5$ and there was marked reduction of both primary and secondary neovascularization (Figs 1 and 2). In May, 1962, however, vitreous bleeding recurred in the right eye and all useful vision was lost following retinal detachment. The patient remained well until June, 1963, when he was admitted in a coma of several hours' duration, with convulsions, and a blood sugar of $40 \mathrm{mg}$. per cent. Despite correction of the hypoglycaemia, the use of anticonvulsants and antipyretic drugs, he never regained consciousness, became hyperpyrexial, and died fifteen hours later. At post-mortem no pituitary tissue was found; the brain showed widespread petechial haemorrhages and death was ascribed to the irreversible effects of prolonged hypoglycaemia on the central nervous system.

Case 2.-This patient reported to the diabetic department in August, 1962, after an absence of ten years, because of sudden blindness in his left eye. In this eye vision was reduced to perception of hand movements, there being advanced secondary neovascularization and a large fresh vitreous haemorrhage. The visual acuity in the right eye was $6 / 9$ and N 8. This retina showed scattered small pre-retinal haemorrhages and micro-aneurysms, a few hard exudates in the macular region, and sheathing of many peripheral vessels; the outstanding lesion, however, was an extensive lacework of primary new-vessel formation surrounding the macular region. Pituitary stalk section was performed on September 18, 1962. In the left eye the vitreous haemorrhage resolved, with less secondary neovascularization and fibrosis than might otherwise have been expected, and acuity improved to $6 / 60$. No further bleeding occurred in the right eye, the vascular sheathing became less marked, the haemorrhages resolved without organization, and the network of new capillaries disappeared, leaving only a few delicate strands of fibrosis. However, a year after surgery a few localized areas of new, primary neovascularization were noted; these have regressed spontaneously without bleeding or significant fibrosis, but new areas continue to appear and regress. The visual acuity in this eye is now $6 / 6$ and $\mathrm{N} 5$.

Case 3.-He lost the sight of his right eye in 1956 following a massive vitreous haemorrhage. Since 1959 repeated haemorrhages had occurred in the left eye and he was referred to us in October, 1962. He could only count fingers with his right eye, and visual acuity in the left was 6/12 and N 5 . In both retinae there was extensive secondary neovascularization (Figs 3 and 4) and several fresh areas of bleeding were seen. The left macular region was destroyed by fibrosis, but the right macula was as yet spared, although there were several small haemorrhages adjacent to it. Operation was carried out on October 25, 1962. Following surgery the haemorrhages resolved, the neovascularization regressed considerably, and, although three or four small haemorrhages have since occurred in the left eye these have quickly cleared without fibrosis. The visual acuity in the right eye has improved to $6 / 60$ and $N 12$ and in the left remains at 6/12 and N 5 .

Case 4.-This patient was referred in January, 1963, following eight years of deteriorating vision. Eighteen months previously he had lost the sight of the right eye and since then had suffered at least one major and several minor haemorrhages in the left eye. In the right eye there was advanced secondary neovascularization with retinal detachment, vision being reduced to counting fingers. In the left a large ring of vascularized fibrous tissue extended from the disc to surround the macula and reached out into the vitreous; fresh vitreous and retinal haemorrhages were present and the visual acuity corrected to 6/24 and N 8. Pituitary stalk section was carried out on January 14, 

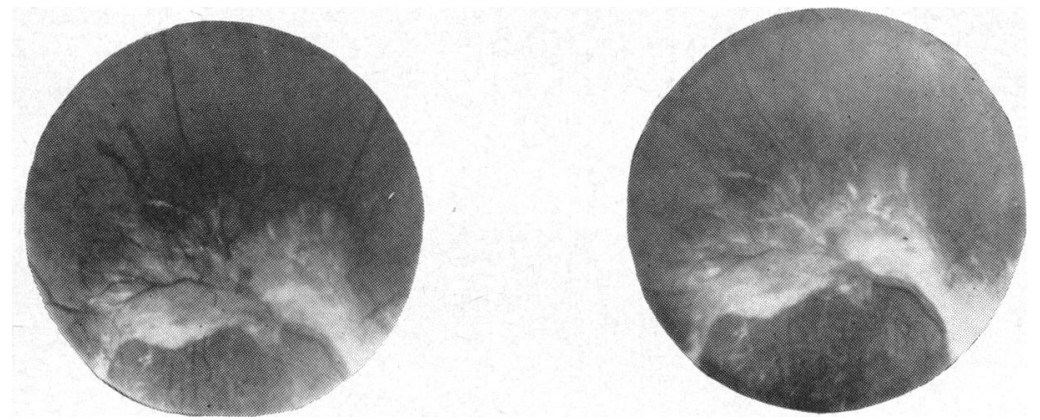

FIG. 3.-Case 3, right eye. Secondary neovascularization encircling the macula before, and 2 years after, operation.
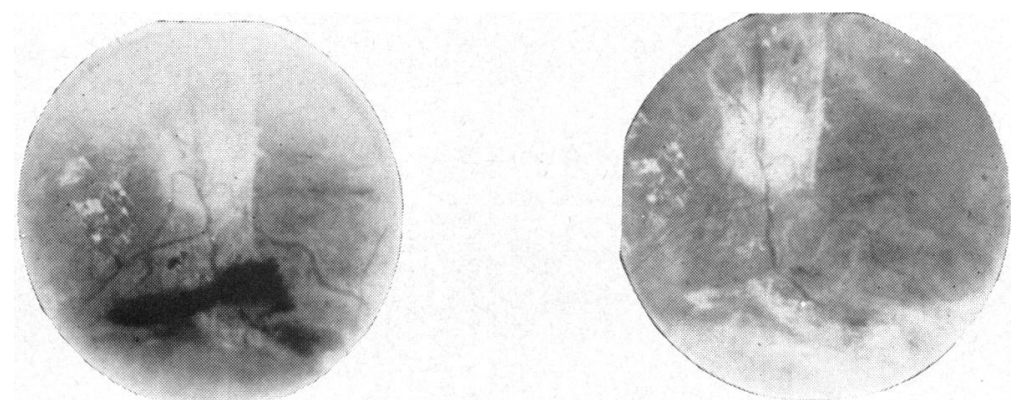

FIG. 4.-Case 3, left eye. Secondary neovascularization and pre-retinal haemorrhage before, and 14 months after, operation.

1963. Following surgery neovascularization regressed; two further small vitreous haemorrhages occurred in the left eye, but cleared rapidly without fibrosis and the visual acuity remains at $6 / 24$ and $\mathbf{N} 8$.

Case 5. - She first experienced visual symptoms in January, 1962, when a large vitreous haemorrhage occurred in her right eye; this cleared after ten months, revealing extensive secondary neovascularization and retinal detachment, the visual acuity being reduced to counting fingers. In the left eye the visual acuity was $6 / 18$ and $\mathrm{N} 5$. This fundus showed scattered micro-aneurysms, round haemorrhages, and some central exudates; there was primary neovascularization on the margin of the optic disc and along the upper temporal vessels in the mid-fundus, and the veins showed characteristic changes of diabetes. These features remained unaltered until January, 1963, when a large vitreous haemorrhage temporarily reduced vision in the left eye to less than $6 / 60$. Pituitary stalk section was carried out on February 8, 1963. The left vitreous haemorrhage cleared fairly rapidly, leaving only a fine band of fibrous tissue extending from the disc towards the macula; the primary neovascularization has disappeared, some improvement has occurred in the veins, and no further haemorrhages have occurred (Fig. 5). Vision in this eye is 6/12 and N 5. The right fundus remains relatively unchanged.

Case 6. - He had noticed visual deterioration for a year before referral to us in February, 1963. Visual acuity was $6 / 18$ and $N 5$ in the right eye and 6/18 and N 8 in the left. In both fundi there were marked venous dilatations and irregularities, early new vessel formations, scattered preretinal and retinal haemorrhages, and fine macular exudates; there was no secondary neovascularization or fibrosis and no evidence of vitreous haemorrhage. Despite the presence of generalized atherosclerotic vascular disease, which had necessitated amputation of the left leg for gangrene, operation was undertaken on April 15, 1963. Unfortunately, he developed a left hemiplegia following severe hypotension and although motor power gradually returned he was left with marked personality changes. Visual acuity could not be assessed accurately, but there was considerable clearing of haemorrhages and very marked regression of new vessel formation 

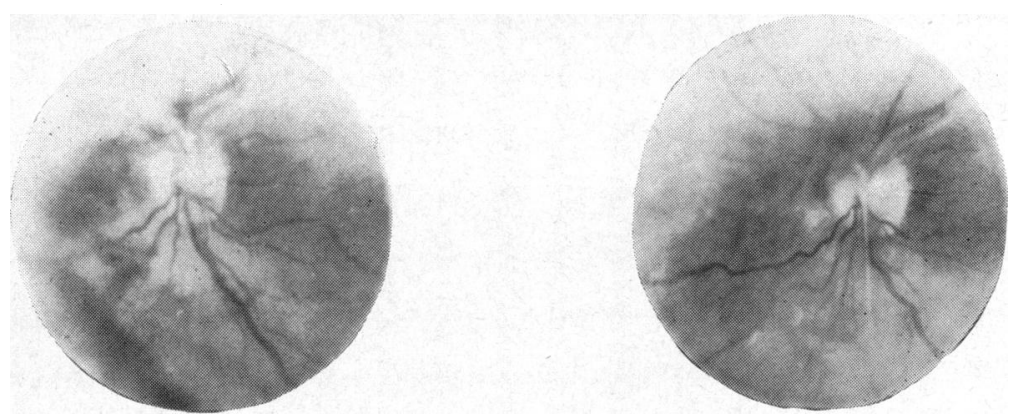

Fig. 5.-Case 5, left eye. Before, and 6 months after, operation.
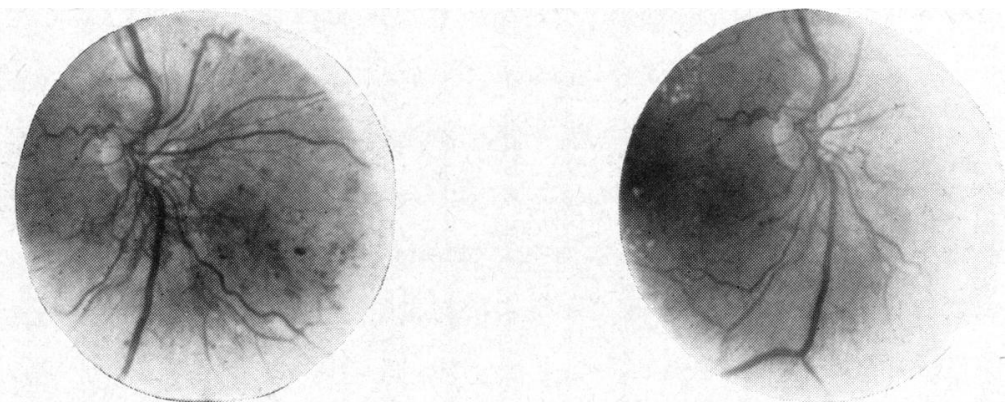

Fig. 6.-Case 6, right eye. Primary neovascularization and venous changes before, and 4 months after, operation.
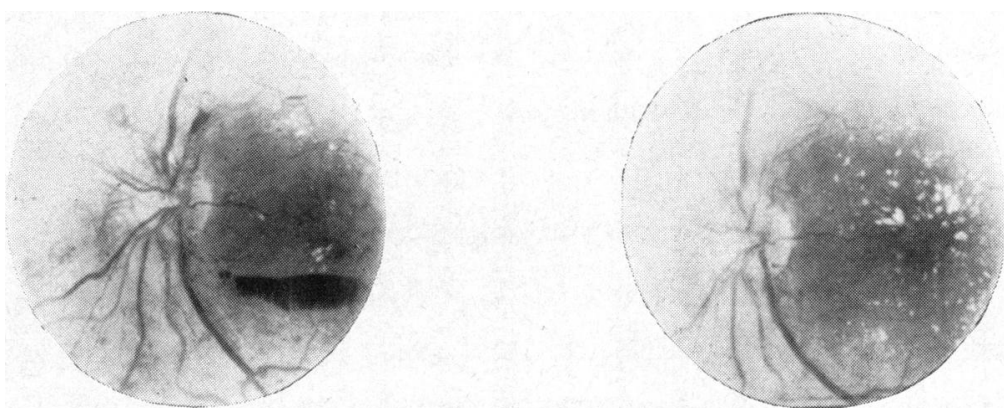

Fig. 7.-Case 6, left eye. Primary neovascularization, venous changes and pre-retinal haemorrhages before, and 4 months after, operation.

(Figs 6 and 7). In February, 1964, he died elsewhere, following a myocardial infarct. This was confirmed at necropsy, which also demonstrated total occlusion of the right anterior cerebral artery, which had presumably occurred at the time of post-operative crisis. The pituitary gland appeared to be intact, but unfortunately was not examined histologically.

Case 7.-This patient was referred in December, 1962, when he was found at routine examination in the diabetic department to have marked bilateral retinopathy with venous changes, widely scattered superficial and retinal haemorrhages, and some central exudates. He had no subjective ocular symptoms, and visual acuity was $6 / 9$ and $N 5$ in the right eye and $6 / 6$ and $N 5$ in the left. A year later new vessel formation was noted in the region of both discs and the haemorrhages were more numerous; visual acuity remained unchanged. In May, 1964, a large pre-retinal haemorrhage occurred in the right eye reducing visual acuity to 6/24 and N 12 and ophthalmoscopy showed advancement of both the venous changes and primary new vessel formation in both eyes. The occurrence of pre-retinal haemorrhages in the left eye shortly thereafter led to surgery being 

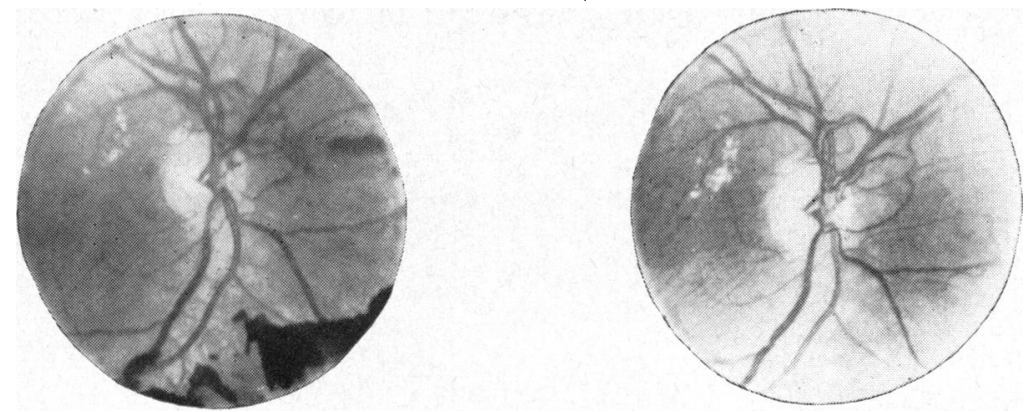

FIG. 8.-Case 7, right eye. Before, and 3 months after, operation.

undertaken on June 9, 1964. It was originally intended to treat the patient by ${ }^{90}$ yttrium implantation, but because of chronic paranasal sinus infection pituitary stalk section was preferred. Since operation there has been some improvement in the retinopathy (Fig. 8), but this has been slower and less marked than in our other cases. Furthermore, his post-operative insulin requirements have not fallen as much as expected, suggesting that only partial pituitary ablation has been achieved.

\section{Discussion}

Although the immediate post-operative mortality following pituitary stalk section is less than that following formal hypophysectomy it is not inconsequential, having occurred in 3 out of 53 patients reported in other series (Field, Schepens, Sweet, and Appels, 1962; Contreras, Field, Hall, and Sweet, 1962; Gordon and Javid, 1962; Lundbaek, Malmros, Andersen, Orht, and Jensen, 1962; Field, Sweet, McMeel, Germanos, and Schepens, 1963).

Because of the immediate and the long-term effects, careful selection of patients is imperative. In retrospect, we feel that the pre-operative assessment of Case 1 was inadequate, and that, although ophthalmologically a success, Case 6 should not have been operated upon because of the extent of his generalized vascular disease. Both died within sixteen months of operation. We believe that another contraindication is severe autonomic neuropathy, but that milder forms of diabetic neuropathy are acceptable, as is diabetic nephropathy unless the renal disease is so advanced as to limit the life expectancy to less than five years. Consequently we reject patients with a nephrotic syndrome or with a creatinine clearance of less than $40 \mathrm{ml}$. per minute.

The long-term dangers of pituitary ablation, namely, hypoglycaemia and adrenal insufficiency, can be minimized by careful education of the patients in the principles of self-regulation of insulin and cortisone requirements, and by ensuring that they carry both dextrosol and glucagon to use should hypoglycaemia develop. Patients must be sufficiently intelligent to understand the principles involved.

The surviving five patients are, so far, considered to be successes; they all feel extremely well, have returned to their former occupations, and have achieved good diabetic control on reduced insulin requirements. Visual acuity has improved subjectively in Cases 2, 3, and 5, is improving in Case 7, and has not deteriorated in Case 4. The beneficial effect on the retina is indisputable, as has been described in the case reports, and examples of the changes noted are given in the illustrations. 
The first sign of improvement is usually reduced vitreous turbidity, due to increased rate of absorption of vitreous haemorrhage, and this may be apparent within fortyeight hours of operation (Field and others, 1962). Otherwise, the beneficial effects do not occur for some weeks, during which period further haemorrhage may take place. Thereafter, haemorrhagic activity can be expected to lessen or cease, and those haemorrhages that occur absorb more rapidly and clear without fibrosis. Primary neovascularizations may completely regress and secondary neovascularizations also respond, becoming less vascular and more condensed, such improvement being noted even in severely damaged eyes. Avascular fibrous tissue bands, however, cannot be expected to show any improvement. The vascular improvement continues for three months or longer, and the final picture observed in our advanced cases is similar to that described by Beetham (1963) in the 10 per cent. of his patients where there was spontaneous arrest of the retinopathy. This emphasizes the importance of repeated pre-operative ocular examinations to ensure that the condition is progressive and is endangering vision. On the other hand, our most impressive ocular results have occurred in those patients with primary neovascularization, and it would appear that the ideal time to operate is before significant secondary changes have developed. The exact mechanism whereby pituitary ablation influences diabetic retinopathy is unknown, but may be related to a reduction in the blood plasma of the protein-bound insulin antagonists.

There has been no appreciable deterioration in renal function as assessed by creatinine clearance estimations, urinary and serum protein measurements, and histological changes in those follow-up renal biopsies so far obtained, and it may be that pituitary ablation is also exerting a beneficial effect on the diabetic nephropathy.

The best clinical evidence of satisfactory pituitary ablation appears to be the reduction in insulin requirements. This has been observed in all our patients but in Case 7 the fall in insulin dosage has been less marked than usual, as has been the ophthalmological improvement. It may be that in this case stalk section has only effected partial pituitary insufficiency as described by Javid, Gordon, and Erickson (1958). This possibility must always be considered before subjecting any patient to pituitary stalk section.

Where post-operative measurements have been carried out, our patients have shown clinical evidence of hypothyroidism with falling serum thyroid stimulating hormone levels before the introduction of thyroxine replacement therapy. The effect on urinary gonadotrophin excretion has been more variable, and one patient (Case 4) now has normal levels of gonadotrophin but no other evidence to suggest reactivation of pituitary function.

Post-mortem examination was performed on the two patients who died. No pituitary tissue was found in Case 1, but unfortunately the pituitary gland was not examined histologically in Case 6.

Although stalk section is an accepted method of producing pituitary insufficiency, we have now abandoned it as a primary procedure in favour of ${ }^{90}$ yttrium implantation, because this technique is less hazardous and may be as effective. However, the degree and duration of pituitary insufficiency produced by ${ }^{90} \mathrm{yttrium}$ implantation are also still undefined. It will be some years before a final assessment of the two procedures can be made, but we now reserve stalk section for cases where ${ }^{90}$ yttrium 
implantation has failed or is contra-indicated because of paranasal sinus infection (e.g., Case 7).

By using ${ }^{90}$ yttrium it may prove possible to relax the ocular criteria and operate at an earlier stage, but like Field (1963), we believe that operation should be deferred until subjective symptoms develop. Moreover, patients who for medical reasons or age might be considered unsuitable for stalk section, remain potential candidates for ${ }^{90}$ yttrium implantation, since the immediate post-operative disturbance is minimal.

\section{Summary}

The indications for pituitary stalk section in advancing diabetic retinopathy are discussed. The ophthalmological and medical criteria for selection of patients are laid down, and the pre-operative and post-operative management of the patient described. In this series all seven patients survived the procedure but two have died within sixteen months of operation, one of myocardial infarction, the other from irreversible hypoglycaemia. The results in regard to improvement or arrest of retinopathy are encouraging and, if a simpler and equally effective method of inducing pituitary insufficiency is available, then this procedure could be offered to a wider group of diabetic patients.

We are indebted to Prof. G. I. Scott for encouraging us to undertake this work, to Prof. Emeritus Norman M. Dott, who performed the first two operations, to Prof. F. J. Gillingham, who operated on Cases 3 and 5 , and to Mr. J. F. Shaw, who operated on Case 6. We are grateful to Dr. J. Ronald, Inverness, for referring Cases 1 and 4, and to Dr. W. A. L. MacFadyen, Blackburn, for Case 6, and we would also like to acknowledge the very considerable help given to us by Prof. L. G. Whitby and his Department of Clinical Chemistry. Our thanks are also due to the resident and nursing staff of the Royal Infirmary of Edinburgh who cared for the patients after operation, and to Mr. A. McDonald of the Department of Ophthalmology, who carried out the retinal photography and prepared the illustrations for this paper.

\section{ADDENDUM}

Since this paper was submitted for publication 2 patients (Cases 3 and 5) have each had a large vitreous haemorrhage in their better eye, reducing visual acuity to perception of hand movements. Both haemorrhages are clearing and in Case 3 visual acuity in June, 1965, was 6/60 and N36, and in Case 5 6/18 and N14. Case 4 has had an episode of severe adrenocortical insufficiency requiring admission to hospital. The visual acuity in his left eye has improved to 6/18 and N5 (July, 1965). In Cases 2 and 7 visual acuity remains as stated in Table II.

\section{REFERENCES}

BeEtham, W. P. (1963). Brit. J. Ophthal., 47, 611.

Contreras, J. S., Field, R. A., Hall, W. A., and Sweet, W. H. (1962). Arch. Ophthal., 67, 428.

Dunlop, D. M., and Duncan, L. J. P. (1957). J. roy. Coll. Surg. Edinb., 3, 81.

Field, R. A. (1963). In Discussion on Hypophyseal Stalk Section, Hlghts Ophthal., 6, 282. , Schepens, C. L., Sweet, W. H., and Appels, A., (1962). Diabetes, 11, 465.

, Sweet, W. H., McMeel, J. W., Germanos, R. P., and Schepens, C. L. (1963). Un. méd. Can., 92, 1297.

Gordon, E. S., and JAVID, M. (1962). Diabetes, 11, 470.

JAVID, M., Gordon, E. S., and ERICKson, T. C. (1958). J. Neurosurg., 15, 504.

Luft, R., Olivecrona, H., IkKos, D., Kornerup, T., and LJungGren, H. (1955). $\quad$ Brit. med. J., $2,752$.

$\longrightarrow,-$ and SJögren, B. (1952). Nord. Med., 47, 351.

Lundbaek, K., Malmros, R., Andersen, H. C., Orht, V., and Jensen, V. A. (1962). Diabetes, 11, 474.

Poulsen, J. E. (1953). I Ibid., $2,7$.

SPRAGUE, R. G. (1962). I Ibid., 11, 491. 